\title{
ARQUITECTURA TEATRAL EN LA CORUÑA. EL SIGLO XIX: EL TEATRO DE LA FRANJA O DE VARIEDADES (1823-1889)
}

\author{
por \\ JESUS ANGEL SANCHEZ GARCIA
}

El estudio de la arquitectura teatral en Galicia tiene como principales puntos de interés aquellos recintos construidos en los años centrales y finales del siglo XIX, y que, bajo la denominación genérica de teatros burgueses, constituyen una de las tipologías arquitectónicas más importantes de la época. Todas las ciudades gallegas de cierta relevancia contaron con teatros de este tipo, algunos de los cuales, como el Rosalía de Castro de La Coruña, el Jofre de Ferrol o el Principal de Orense, aún hoy en día, con mayores o menores alteraciones, se mantienen en uso.

Sin embargo, el camino hasta la consolidación de este modelo concreto se vió jalonado por numerosas construcciones que, desde la aparición de los primeros edificios teatrales gallegos, en el último tercio del siglo XVIII, fueron incorporando progresivamente elementos tan definitorios como los palcos, las salas en curva o a la italiana, los espacios para el descanso de los asistentes (foyer, ambigú), etc... Estos primeros teatros, de una entidad material bastante precaria en la mayoría de las ocasiones, apenas han concitado el interés de los estudiosos, de manera que su categoría como ensayos o precedentes de los grandes teatros decimonónicos es bastante desconocida.

En el caso que nos ocupa, la ciudad de La Coruña, los primeros recintos

"CUADERNOS DE ESTUDIOS GALLEGOS", Tomo XL, Fascículo 105, Santiago 1992. 
específicamente teatrales se construyeron gracias a la iniciativa de un curioso empresario de óperas italiano, llamado Nicolá Setaro, arribado a la urbe tras un largo periplo por diferentes ciudades portuarias de la Península ${ }^{1}$. En 1768 levantó un pequeño teatro provisional en la zona del glacis de Puerta Real más cercana a las fortificaciones de la Ciudad Vieja, con una corta vida ya que al año siguiente sería demolido por las autoridades militares. El mismo Setaro construiría otro teatro con mayores ambiciones en 1770, situado en parte de lo que luego fue la Plaza de los Huevos (hoy Plaza del Humor) y que se mantuvo en pie hasta que un incendio lo destruyó en 18042 .

El mismo emplazamiento del primer teatro de Setaro sirvió para levantar, tras el citado incendio, uno nuevo a cargo del empresario de comedias Bartolomé Alegre, y bajo la dirección del arquitecto de la ciudad D. Fernando Domínguez Romay ${ }^{3}$. Concebido como un recinto provisional, las penosas circunstancias del país hicieron que su existencia se prolongara desde 1804 a 1823. En esa última fecha, el asedio a que fue sometida la plaza de La Coruña por parte de las fuerzas absolutistas hispano-francesas, en los meses de Julio a Agosto, trajo consigo su total destrucción. La ciudad perdió así el que

\footnotetext{
${ }^{1}$ Véase al respecto, CARREIRA, X.: El teatro de ópera en la Península Ibérica ca. 1750-1775. Nicolá Setaro, en De música hispana et aliis, Universidad de Santiago, 1990. Vol. II, págs. 27 a 117.

${ }^{2}$ Sobre estos primeros teatros coruñeses se encuentran referencias en estudios locales como los de:

VEDIA Y GOOSSENS, E. de: Historia y descripción de la ciudad de La Coruña. Imp. Domingo Puga, La Coruña, 1845. Págs. 128 y 270.

MADOZ, P.: Diccionario Geográfico-Estadístico-Histórico de España y sus posesiones de Ultramar. Madrid, 1847. Pág. 403.

TETTAMANCY Y GASTON, F.: Apuntes para la historia comercial de La Coruña. Tip. de El Noroeste, La Coruña, 1900. Págs. 214 a 220.

CARRE ALDAO, E.: Provincia de La Coruña en Geografía General del Reino de Galicia. Volumen V, tomo 2ำ (Ed. facs. Ediciones Gallegas, La Coruña, 1980). Pág. 641. Y más recientemente en los trabajos de:

SORALUCE BLOND, J. R.: El espacio del espectáculo: los primeros teatros de Galicia en Boletín Académico de la E.T.S.A. de La Coruña, 1988, nº 9. Págs. 26 a 37. VIGO TRASANCOS, A.: La arquitectura teatral en La Coruña del siglo XVIII en Rev. José Cornide, nº 26, La Coruña, 1991, págs. 125-152.

${ }^{3}$ Para un estudio más detallado de las características de este Teatro Provisional de Puerta Real, cuya existencia había pasado ignorada hasta ahora, véase: SANCHEZ GARCIA, J. A.: El primer ejemplo de teatro "a la italiana" en La Coruña: Fernándo Domínguez Romay y el Teatro Provisional de Puerta Real (1804-1823), en Rev. Abrente (en prensa).
} 
durante veinte años fuera su único recinto teatral, escenario tanto de representaciones dramáticas como de bailes de máscaras, festejos patrióticos, etc.

Perdido su medio de subsistencia, los cómicos que se encontraban representando en aquel modesto teatro pronto se movilizaron para conseguir otro local donde poder continuar con las funciones, aunque fuese de forma provisional. En esta ocasión, de acuerdo con un informe elaborado por el Gobernador Militar, biéndose los cómicos sin teatro alguno para representar se han combenido con D. Bernardo del Río, vecino de ella y dueño del edificio llamado Salón filarmónico, y éste se lo aprestó, dispuso y reparó de modo que en él han travajado aunque con bastante estrechez hasta la conclusión de la temporada... ${ }^{4}$.

Este Bernardo del Río es el hijo del autor de una descripción de la ciudad y provincia de La Coruña redactada en el año 1800 con destino al Diccionario Geográfico de España que estaba preparando el geógrafo y cartógrafo D. Tomás López ${ }^{5}$. No conocemos más datos sobre su persona, pero sí sabemos que su Salón filarmónico se encontraba situado en la calle de la Franja, en un edificio levantado en parte del mismo solar escogido en 1767 para ubicar un proyecto de teatro diseñado por el ingeniero Feliciano Míguez (Láminas I y II) -proyecto que finalmente no se ejecutó con lo que el solar permaneció muchos años como almacén de leña y otros utensilios del ejército-. Debía tratarse de una sala particular para celebrar pequeñas veladas musicales o tertulias, diversiones muy del gusto de la burguesía decimonónica, que ahora va a ser habilitada como provisional teatro, colocando apresuradamente un escenario y algunos bancos y palcos. Desde Octubre a Diciembre de 1823 aparecen en los Libros de Actas Municipales referencias a las funciones allí realizadas, a cargo de la compañía de Pascual Boix.

Llegado el nuevo año, el 5 de Febrero se examinó en el Ayuntamiento un prospecto hecho para hacer un Coliseo en esta Ciudad en veneficio del Hospital de Caridad y Niños expósitos de la Ynclusa; la falta de más noticias sobre esta iniciativa municipal para edificar un nuevo teatro nos hacen

\footnotetext{
${ }^{4}$ Archivo Municipal de La Coruña. Sección de Teatro, caja 1809-1833. Legajo 1824. Escrito de D. León de la Cámara sobre la conducta de los cómicos durante la fatal y desgraciada época revolucionaria. 31 de Marzo.

${ }^{5}$ A Bernardo del Río padre (1750-1811) se refieren las noticias contenidas en el artículo de MARTINEZ-BARBEITO, C.: Bernardo del Río describe La Coruña de fines del siglo XVIII en Revista José Cornide, núm. 2, 1966 (año II). Págs. 39 a 58.
}

"CUADERNOS DE ESTUDIOS GALLEGOS", Tomo XL, Fascículo 105, Santiago 1992. 


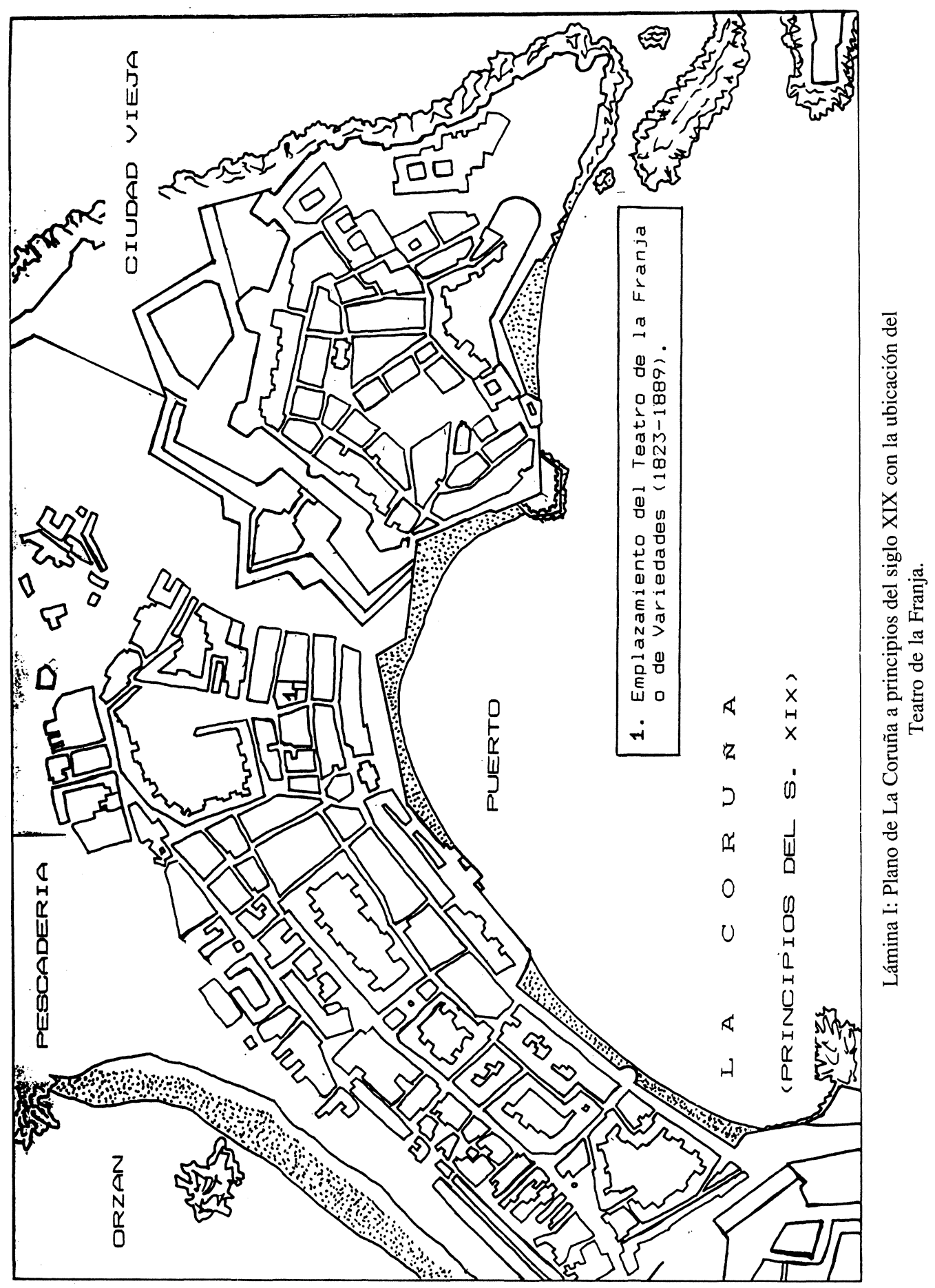




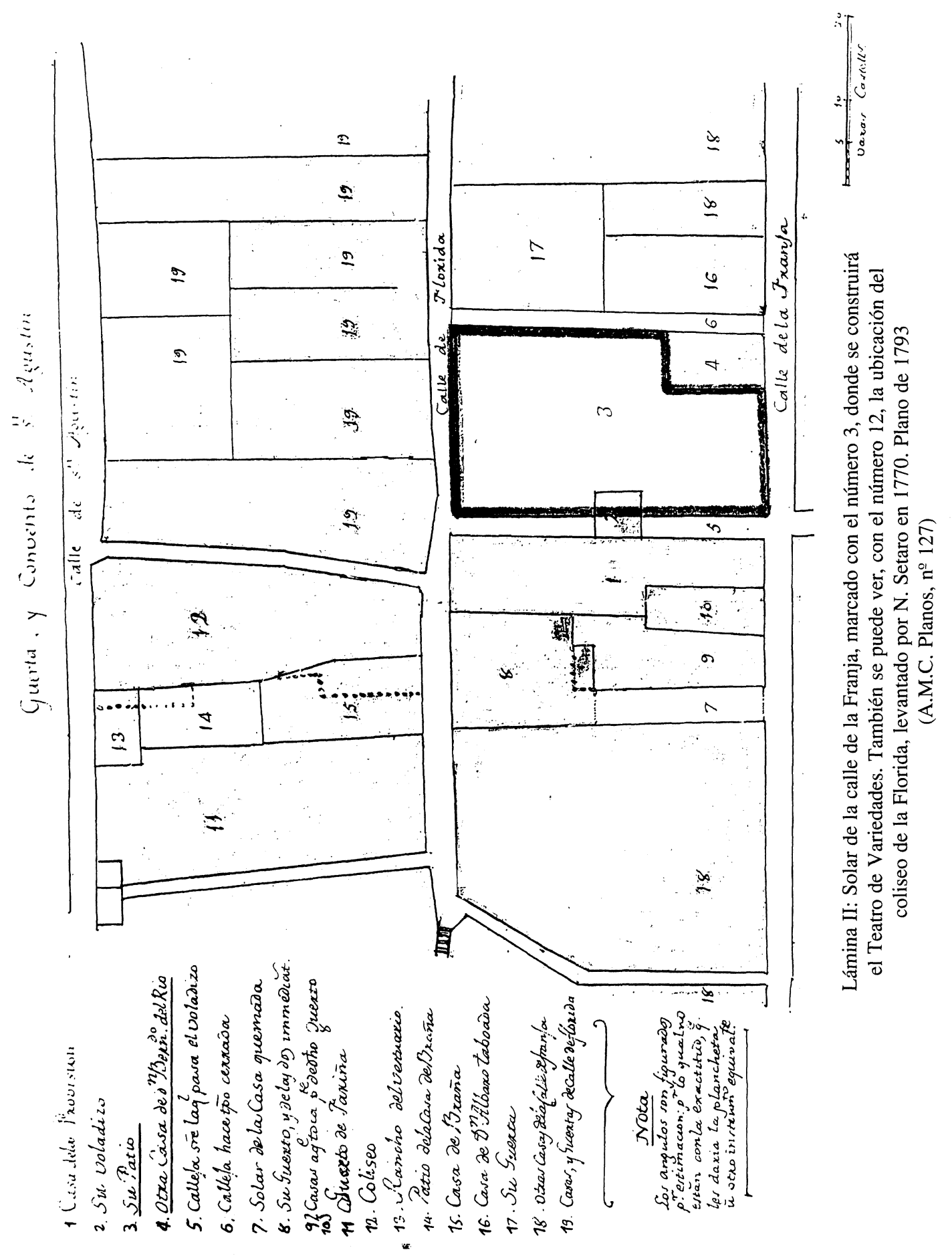


suponer que acabó por ser desestimada ante las obras de ampliación emprendidas poco después por Bernardo del Río en su local. En efecto, volviendo al testimonio de D. León de la Cámara, acabada la temporada cómica, tras los carnavales. ...el citado Río(s) trató de alargar el indicado edificio y darle alguna más capacidad para que los autores pudieran representar con más comodidad y los espectadores tubiesen el deshaogo necesario y en efecto en el día se trabaja con bastante actividad en dicha obra... ${ }^{6}$.

En el mes de Mayo todavía continuaban estas reformas, lo cual nos da alguna idea de su importancia. Según todos los indicios, como luego veremos, el arquitecto que se encargó de diseñar el trazado del nuevo teatro fue el académico y titular de la ciudad D. Melchor de Prado y Mariño (17801834). Nacido en Santiago y arquitecto académico desde 1796, entre otras edificaciones es autor de las iglesias compostelanas de San Benito del Campo y San Miguel dos Agros, además de la Colegiata de Vigo. Ya en La Coruña, al morir Fernando Domínguez Romay fue nombrado arquitecto titular el 14 de Julio de 1818, cargo que desempeñó hasta su fallecimiento el 23 de Enero de 1834 ?.

Según un informe de este facultativo, el edificio teatral en obras se estaba realizando con la solidez precisa, por lo que a su juicio: será firme y estable por muchos años atendiendo a que todas las maderas que forman su esqueleto son de roble y de castaño... ${ }^{8}$. Otro reconocimiento paralelo, debido al ingeniero militar Dámaso de Aldao, se muestra menos complaciente y advierte que La angostura del local de este Teatro, tal vez será la causa de que las cruji(d)as de los palcos, y la Escalera sean demasiado estrechas, cuia falta es bastante notable... . Además de recomendar la colocación de más correas en la armadura del tejado, subraya que en la fachada se (h)abran otras dos (puertas) a los costados de la principal, y otra en la

\footnotetext{
${ }^{6}$ Vid. nota 4.

${ }^{7}$ Para completar estos datos sobre Melchor de Prado y Mariño véase:

MURGUIA, M.: El arte en Santiago durante el siglo XVIII. Est. Tipográfico de Ricardo Fe, Madrid, 1884. Pág. 227.

COUSELO BOUZAS, J.: Galicia artística en el siglo XVIII y primer tercio del XIX. Imp. y Lib. del Seminario, Santiago de Compostela, 1933. Págs. 549 a 552.

NAYA PEREZ, J.: Noticia histórica de las galerías coruñesas y relación de arquitectos de La coruña desde que se creó el cargo hasta el presente. Instituto José Cornide de Estudios Coruñeses, La Coruña, 1965. Págs. 67 y 68.

${ }^{8}$ A.M.C. Caja Varios, año 1823-24. Legajo 1824. 4 de Mayo.
} 
pared de la Calle colateral... ${ }^{9}$.

Con estas modificaciones quedaría ya totalmente conformado este Teatro de Bernardo del Río, Teatro de la Franja, Teatro viejo o Teatro de Variedades, nombres con los que se le conocerá sucesivamente a lo largo de la centuria. A pesar de la amplitud cronológica de su existencia, los datos que hemos podido recopilar acerca de sus características son más bien escasos y sin ningún tipo de documentación gráfica que pueda ilustrarlos.

La descripción más completa del mismo la realiza Pascual Madoz, aunque ya a la altura de 1847, en el apartado de su Diccionario dedicado a los principales edificios de la ciudad:

"TEATROS. El sit. en la calle de la Franja, conocido vulgarmente por el Teatro Viejo, nada notable por sus dimensiones ni arquitectura, presenta una fachada de 52 pies' de frente y tres puertas que dan entrada a un reducido vestíbulo o mejor dicho zaguán; el primero y segundo cuerpo reciben la luz por tres ventanas cada uno, y sobre la cornisa que corona el edificio, hay una boardilla en toda la estensión. El interior es de figura elíptica, y el foro o escenario, está colocado desde uno de los focos de la curva hasta la fachada posterior: la long. contada desde una a otrafachada es de 108 pies, su mayor dimensión en el interior de la curva (es) de 50 pies hasta el foro, y éste tiene 28 de longitud: la altura que es de 29 pies está ocupada por tres órdenes de asientos que son: palcos bajos, principales y galería, y todo él proporciona localidad para 600 personas: hay además dos pequeños salones sobre el vestíbulo, y así los pasillos como las escaleras son estrechas e incómodas. Todo el interior es de madera de roble y pino del país..." ${ }^{10}$.

${ }^{9}$ Idem, Caja Teatro: expedientes personales, informes y orden público (1767-1960). Legajo 1824: Informe sobre condiciones de seguridad del teatro de la Franja encargado por el Subdelegado del Protector de Teatros del Reino. 5 de Mayo.

${ }^{10}$ MADOZ, P.: Diccionario Geográfico-Estadístico-Histórico de España y sus posesiones de Ultramar. Madrid, 1847. Pág. 403.

Soraluce Blond, en su artículo dedicado a los primeros teatros de Galicia, comete varias inexactitudes en relación a este Teatro Viejo puesto que no sólo lo confunde con el de Puerta Real, veinte años anterior, sino que atribuye su autoría a Fernando Domínguez Romay, que había fallecido en 1818.

Véase SORALUCE BLOND, J. R.: El espacio del espectáculo: los primeros teatros de Galicia, en Boletín Académico de la E.T.S.A. de La Coruña no 9, 1988. Págs. 35 y 36.

"CUADERNOS DE ESTUDIOS GALLEGOS", Tomo XL, Fascículo 105, Santiago 1992. 
Gracias a estos datos sabemos que en su imagen externa el edificio teatral seguía acomodándose a la arquitectura doméstica más común en la ciudad: con una tipología de vivienda con bajo y dos pisos, reparto simétrico de los vanos y fayado superior. Estaba situado en el número 22 de la calle de la Franja y, además de las tres puertas dispuestas en la fachada principal, existía una de emergencia en su pared medianera izquierda, hacia la calle de la Trompeta, y otras dos, tras el escenario, en la fachada trasera a la calle de la Florida.

En el interior un pequeño vestíbulo, probablemente con los despachos para venta de billetes y guardarropa, daba paso a la sala y estructura de palcos dispuestos en tres niveles. Al igual que ocurría con su antecesor, el Teatro Provisional de Puerta Real, esta sala formaba una curva que vuelve a ser identificada como elíptica, aunque la alusión a la colocación del escenario truncándola en uno de sus focos y las dimensiones especificadas por Madoz parecen indicar que ahora se trataba de una elipse perfecta. De este modo, el tipo de sala en curva o a la italiana estaba ya perfectamente asumido en la ciudad veinte años antes de construirse el Teatro principal, luego Rosalía de Castro.

Los tres órdenes de localidades en altura eran, de acuerdo con reconocimientos posteriores, 16 palcos bajos o de platea, 18 palcos principales, y una galería superior con gallinero al fondo para las mujeres. Junto con las lunetas o sillas de la platea, proporcionaban originariamente un aforo sufiente para más de 800 personas: una cifra que irá reduciéndose paulatinamente al avanzar el deterioro del recinto; en el año 1833 Melchor de Prado y Mariño ya recomienda que no se sobrepasen las 700 personas, y en 1835 el nuevo arquitecto municipal, D. José María Noya, insiste en respetar la cifra que le calculó el profesor que lo dirigió, en una clara alusión a Prado y Mariño como su autor, precisándola en $684{ }^{11}$.

Como ya señalaba Madoz, uno de los principales defectos de este recinto residía en la estrechez de sus espacios para la circulación del público: pasillos y escaleras principalmente. Esta impresión es refrendada por José María Noya en 1852, quien gráficamente afirma que Los corredores o galerías de los palcos son (tan) sumamente angostas que difícilmente pasa por ellos una persona de frente ${ }^{12}$. Era éste un grave problema para la

\footnotetext{
" A.M.C. Sección de Teatro, caja 1836-67. Legajos 1833, 1836 y 1836-45.

${ }^{12}$ Idem, idem. Caja Teatro: expedientes personales, informes y orden público (17671960). Legajo 1852: Reconocimientos de los teatros de la ciudad. 8 de Noviembre.
} 
seguridad de los asistentes, en caso de ser precisa una rápida evacuación, motivo por el cual a medida que avance el siglo arreciarán las peticiones para el cierre definitivo del teatro.

La casa colindante con la medianera derecha, número 20 de la calle, desempeñaba las funciones de café por medio de varias puertas de comunicación abiertas tanto en la planta baja como en el primer piso ${ }^{13}$. De esta forma, sus habitaciones se añadían a los dos pequeños salones que estaban sobre el vestíbulo de ingreso: incrementando el espacio destinado a estos lugares de descanso y relación social.

A partir del año 1836 crecerá la preocupación por las condiciones de seguridad del teatro, formándose incluso un expediente al respecto. Los arquitectos J. M. Noya y Julián Pastor recomendaron en esa temporada la realización de ciertas obras de reafirmación como apuntalar los palcos principales y la galería, rehacer totalmente las dos escaleras de subida desde el vestíbulo, renovar los pies derechos y pontones torcidos, hacer un cielo raso, etc... Las representaciones fueron suspendidas y hasta el 20 de Noviembre, terminadas esas reparaciones, no se reanudaron, limitando el aforo a 600 personas.

En esta tercera década de la pasada centuria, el teatro de la Franja atravesó por temporadas de gran brillantez, sobre todo en los años previos a la inauguración del Teatro principal en 1840. La ciudad se encontraba entonces alejada de los principales focos de la guerra carlista, con lo que era de las pocas del Norte de España que podía ofrecer un teatro y condiciones normales para representar. Estas circunstancias motivaron la afluencia de compañías líricas y dramáticas de alto nivel, como la de D. José Agostino que en la temporada 1838/39 puso en escena, entre otras óperas: El elixir de amor, El pirata, La extranjera, Belisario, etc... También destacaban por su importancia social los numerosos y concurridos bailes celebrados en su platea (Láminas III y IV).

En 1841 el teatro volvería a ser clausurado por el peligro que suponía la existencia de una viga arruinada en la armadura del techo; esta falla fue subsanada colocando un pie derecho y el recinto pudo reabrirse. Sin

\footnotetext{
${ }^{13}$ En 1881, con motivo de la reedificación de su fachada, se refiere como esta casa forma en rigor una sola finca con el Teatro de variedades del que no es más que una dependencia...

Idem, Sección de Obras, caja 346 (c/Franja). Expediente para la reedificación de la fachada de la casa no 20 . Enero de 1881. Propiedad de D. Ramón del Río.
}

"CUADERNOS DE ESTUDIOS GALLEGOS", Tomo XL, Fascículo 105, Santiago 1992. 


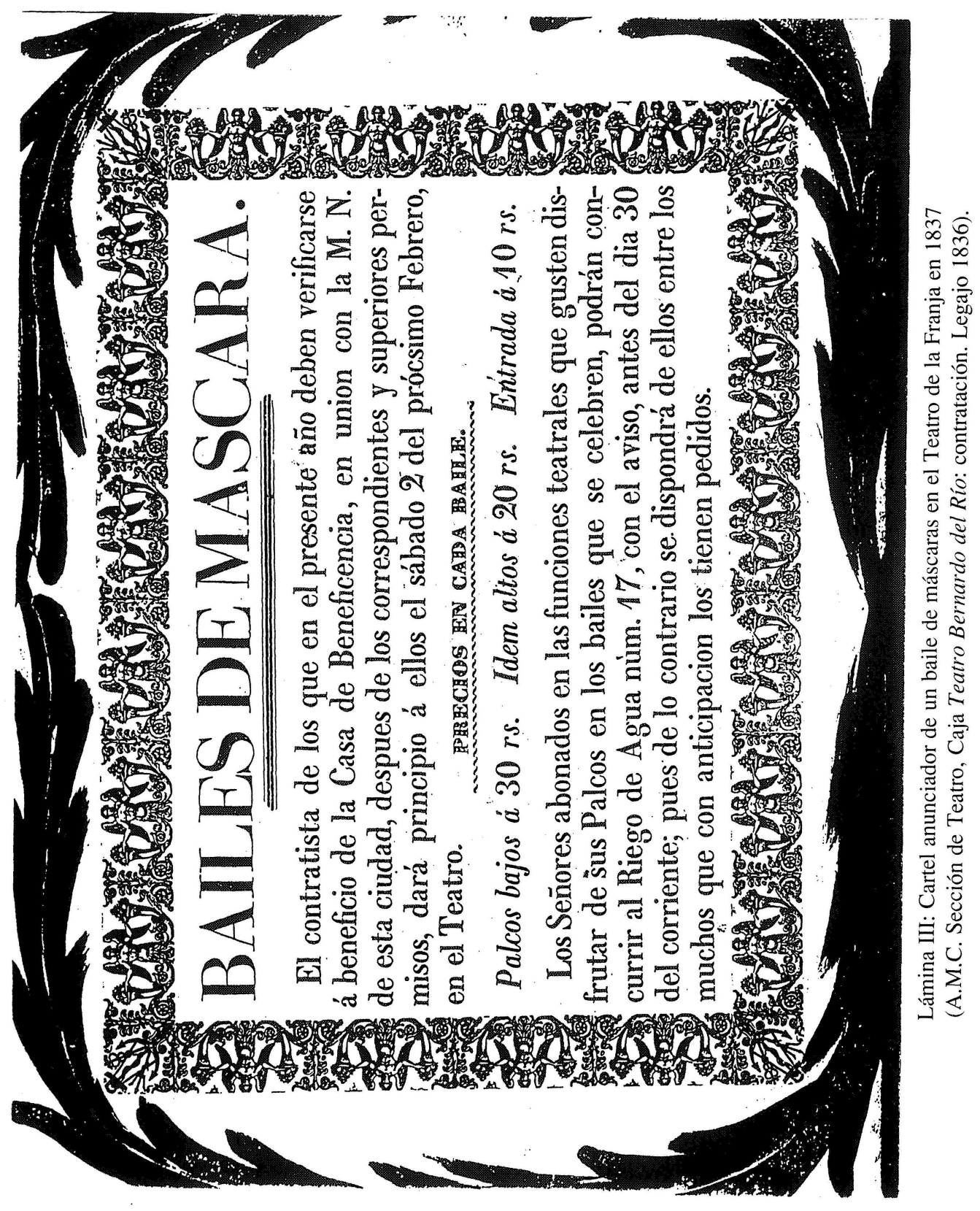




\section{REGLAMENTO QUE EL M. I. AYUNTAM, \\ de esta Ciudad ha formado para el Teatro de la misma, y tendrá esacta obscrvancia desde esta fecha.}

Parle d cargo del Directur de Escena.
1. Los Actores y Actrices

1.- Los Aetores y Actrices se presentarin en la escena con los bacen gusto que corresponde i un Pueblo fino. Oliservario decencia $y$ compostura on sus acciones d movimientoso. Oliservarín lo mayor las reglas de la honestidod y do los principios de una buena educe cion, de modo que puoda decirso con esactitud que el Teasro es la escuela del huen gusto y de las huenas costumbres. Asistirán con puntualidad á sus ejercicios; estudiarton sus popeles y se atendrán í su literal espresion ain quicar, variar o aumentar cose nlgunu, aunigino sea con pretesto de dar nasyor realce $x$ las frnses $\delta$ d la jocosidad.

2.0 Las comparas, bolos y servidumbre, so presentarín limpios $y$ aseados, conto en su personal curoito en sus trajes.

delion ser proporcionatlos a la represcntacion y sicmpre lel escenario, rotiras.

Sc prohile el uso de bastidores ol revés. Las mutaciones delien

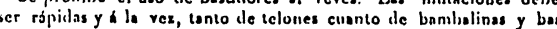
tidores sin observarse en estos varicilad; al efecto es del corbo de $\mathrm{b}$ Comprania cener el número suficiente de sirvientes pars la maniobra.

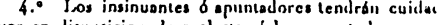
vox en clispusicion de molestor á los espectadores.

5." Se probilite en general la entrada en el esceriario y piezso anlyacentes, a toda clase de persodas estranas i la compania y ant serpreparativos.

los sirvientes de los indiriduos de la Cumpanfa, y los inuchachos ó mugeres que entren con ropas ó recados, saldrín luego que los dejen. Se esceptuan tínicamente los sirviodtes necesarios i los uismos indivisluos prara vestirae of adornarae; pero habrin de permanecer precissmemte dentro do las reapectivas restuarios de los que los ocupen.

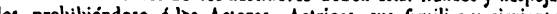
dos, prohibiéndose d los Actores, Actrices, sus funilius y sirvientes cslor en ollos, por que entorpecerian la ejecucion y maniobras. Solo men to para el desempento de sus deberes.

7.0 Is entrada única para cl eerricio de la Compania, es por collo de la Florida : las demas comunicaciones al caccnario estarín cerrados. La puerta do comunicacion sel segundo piso, tombien cer-
rada, teadrá tres llaves iguales, una estorí en el polco do la Ciudad rada, leadrá tres llaves iguales, una estarí en el polco de la Ciudad
para el servicio de orden, otra en poder del Director de escena,

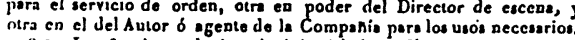
8. - Las funciones darín principio ó la hora Gija qun se anuncie en los carteles, previo icuerdo anterior del M. I. Ayuntamiento ó de caso de un acciden.e ie harbon precisamente las ununciadas. Solo en virierse previo permiso. Parte d cargo del Director de Orquesta.

9.* El Director no permitirá sentarse en el vitio destipado a la orInesta mas que a lus músicos de dotacion.

Caidlara de su orreglo, de que toquen piezas escogidas y bien ensayadiss, y do tule no desconsen durante los intermedios do las piezas

Parte A cargo del Autor.

10. Se protibe la colocacion de sillas ú otros asientos cerca de srquesta y lunetas, $y$ en sus tránsilos, eunque sea con pretesto do

It. Al enpezar la funcion se abririn las cerraduras do lodo' pucrtis de eniracto, lanto los principales cuanto las do lo calo do Florida, queclando eseguradess solemente con un cerrojo calde de Li Sr. Presidente del testro se cerciorará coda dio del cumplimiento ile case disposicion para precover los des bracias denasiado esperimentadas en otros teatros en ocesion de incendio.

12. Aclemas del buen servicio de los 18 quinqués de la srans principal do dotacion, habira el alumbrado correspondiente en el escenario, cn las entradas, transitos y collcjoncs, de forma que despide sccite ó folle de cuidudo. Ilabrá por cuenus de la Comp

vilar en los internedios y para su aseo.

13. Los palcos dobon toner sus correspondientes en coso do desiruirso alguno, so compondrá d recompondri inmedia-

Lo mismo se verificarí con las lunetas.

1/. Ef Antor presentart al M. I. Ayuncouniento los listes firmala dies o al menos on pae pienae cjecutor ha Conponia en cada trein-

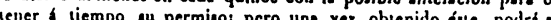
teponerlas ó posponerlas on la ejecucion.
Antea do ofrecer al Público la funcion pora el siguiente dia, lo pondra en conocimiento del Sr. Presidento de semena, I adema le pasari el parte diario de costumbre.

pere estipulados por contrata que son los siguientes.

$$
\text { De noche. }
$$

Entrada ordinario, $2 \mathrm{rs}$. in.--Palcos altos y bajos, 8 ra.--Lunetas, Entracla ordinaria, a rs. in.--Palcos altos y bajos, 8 ri. - - Lunetas, 2
ra.--Gulerías de muger, 12 cuartos. ciones nucyas, á 3 res, la eytrado.

$$
\text { Por la tande. }
$$

Entracha 12 cuartos,--Lunetas i resl-.-Galerias i real.

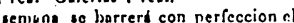
Tentro en general desile las puertas del portal ó entrado principal, lassIa las opuesses de la callo de la filorida, sacándose allí cl polvo o inmundicia, $y$ en eguida se sacudirá y quitará con panos 6 lienzos el polvo do los pralcos y lancias, do modo que los concurrentes no
io numcliell. Si lo cesijicse el aseo so laarrerá al fun dia mas de la semane ó so linipiaré el sitio que lo necesite.

Los sunsideros y comuncs so linpiarán y secorán con srene.

17. No puecten uhonorse mas palcos que lin dos terceras partes de los ventilites. La tercera parte restante qua se destina de pía perniso del aenor Presidente.

En caso de que untes dol mismo ticmpo del despacbo haya pedidos un número mayor de palcos que las disponibles, se formaré acto continuo una lisas en presencis del schor Presidente, y procederá sortearlos con sus correspondientes números entro todos los que lo aliciten, sin distincion ni preferencia alguna, cuidando de evitor e lo posible que se dupliquen nombres distintos para un

Policla d cargo de los Porteros, Alguaciles y Celadores de Proteccion $y$ Seguridad.

Sin embargo do esur 1 su cuidado y rigilancia la eascta obser

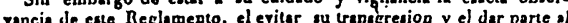
Sr. Presidento do semasa do. las falus quo so cometen, estón $\mathrm{i}$ su car-

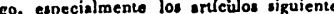

60, 18 . En atencion i lo poca localidad del Teatro se permite solenente fumar on el portal, café y rincones do los tránsitos hajos junto $\alpha$ los faroles a los que sesisten al pátiog lanets, y en los rincones junto $i$ los faroles de los trénsitos álios á los que concurren á los polcos.

19. Por la condicion 14 de la escritura de contrata se la obligodo el Autor í satisfacer al Hospieal de Caridad y Ninos espósito 4,6 y 8 maravelis por cada entrada con proporcion a su precio, y parece razomible que se les moleste al mismo tiempo por pobres que be colocan junto al cobrador y en el portal olistruycudo cl paso; par

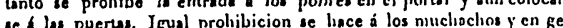
neral toda persona que entorpezca el trónsito.

Nadie podré pararse en los puntos de tránsito a las respectivas localidades, ni en las escoleras, bajo la mula que se cicsignará.

$$
\text { Del Cobrator. }
$$

20. Sin perjuicio del cumplimiento de los obligaciones propias de su encargo y los que le cocan segun esie Reglamento, cuiclará

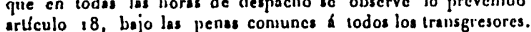
Disposiciones generales.

Do las faltas interiorcs del Escenario es responsable á la $A_{11}$ toridad el Director de Escena, sin perjuicio de la pena que merezco la persona ó personss que les cometan.

Do as lel Trquessa an Director. Las del Púllico que concurro toca direcumente ála Autoridad ó Presidencin eviturlas ó corregirlas. Tumbsien el bacer que el dueño de la cass Teatro cumpla con las obligaciones que le son peculiares. 22. Las folles que se comelan contro lo que esité prevenido en este Reglamento, serín corregidas por la Autoridad con amonestaciout por la primera ves, si fuesen leves, lomandore nola por el Sr. Presidente en el libro o cuaderno que al efecto habra en el palco de ha Ciudad, de lo persona corregida, notivo y feclis en quo lo fué; y en vn. segun su calided.

Corutes darza 25 de 1837

Lámina IV: Reglamento para el funcionamiento del Teatro de la Franja. 1837

(Idem, ídem). 
embargo, desde 1840 al Teatro viejo le había salido un serio competidor en los favores del público como era el recién construido Teatro principal, de mucho mayor aforo y comodidad para el público. Por esta razón, tendía a albergar progresivamente compañías de menor calidad, y cada vez era visto con más recelos por unas autoridades municipales que no ocultaban sus deseos de clausurarlo de forma definitiva.

Un escrito del Alcalde al Gefe Político, en el año 1844, informa que Las maderas del teatro viejo son de pino del país que transcurrido el tiempo que hace está edificado, deben estar podridas algunas de ellas. Para poder pasar con alguna comodidad por el pasillo de los palcos se comió de su espesor a las paredes maestras, y esta circunstancia hace que el edificio no pueda tener la consistencia necesaria..${ }^{14}$. Nuevamente se procedió al cierre del teatro, aunque por las quejas del representante de los herederos de D. Ramón del Río, hijo de su constructor, y la realización de importantes reparaciones desde Abril a Noviembre, terminó por ser reabierto al año siguiente. Probablemente también se mejoró el aspecto interior de la sala con elementos más acordes con las tendencias arquitectónicas contemporáneas, así valorados por Madoz:

"... los arquillos de estilo oriental recién construidos con objeto de cubrir los maderos desnudos colocados para seguridad sobre las divisiones de los palcos bajos y principales, no dejan de producir buen efecto" ${ }^{15}$.

El devenir posterior del edificio, ante la imposibilidad de competir con el Teatro principal, se caracterizará por su uso como sede de las más diversas asociaciones culturales coruñesas, aprovechando las inmejorables condiciones que ofrecían, para albergar sus actividades, el teatro, los salones, e incluso el edificio adosado que había funcionado hasta entonces como café (el número 20 de la calle). Francisco Tettamancy, en su Historia comercial

${ }^{14}$ A.M.C. Sección de Teatro, caja 1836-67. Legajo 1836-45. Expediente sobre la inseguridad del teatro, recomposición y número de personas que pueden caber en las funciones de por la tarde. 22 de Marzo.

${ }^{15}$ Entre esas reparaciones hay que destacar la construcción de un nuevo escenario, la renovación de parte de la armadura del tejado y de los pies derechos que sostenían los palcos, etc...

Idem, ídem.

Véase también MADOZ, P.: op. cit. Pág. 403.

"CUADERNOS DE ESTUDIOS GALLEGOS", Tomo XL, Fascículo 105, Santiago 1992. 
de La Coruña, recoge la cronología fundamental de estas importantes entidades que se ubicaron en el Teatro de la Franja:

"los años de 1845 hasta el 1848, tuvo alquilado este edificio una sociedad de recreo titulada el Liceo, llegando su entusiasmo a poner con todo el lujo y decorado la grandiosa ópera Norma, aparte de otras representaciones dramáticas de gran importancia" ${ }^{16}$.

Refiriéndose a estas mismas fechas, Madoz completa sus apuntes anteriores con la noticia de que el teatro:

"ha recibido notables mejoras en la parte de adorno, decoraciones y pinturas, desde que en los años de 1845 al 1846 lo tomó en arriendo el liceo denominado hoy Sociedad artística y literaria: de estas mejoras han participado el vestíbulo y las entradas, pues aquél ha recibido una forma más graciosa y a las mezquinas puertas que estas tenían, le han sustituido otras más elegantes".

La historia del recinto, hasta su demolición en 1889, vendrá marcada, además, por las constantes quejas con respecto a su seguridad, inmediatamente seguidas de obras de reforma siempre parciales e insuficientes. Con todo, las representaciones teatrales y los bailes -pese a la competencia del Teatro principal-, continuaron desarrollándose gracias al amparo de las diversas asociaciones que los promovían; si bien su ritmo no era el de otras épocas, tampoco conocieron grandes interrupciones como lo atestiguan los informes estadísticos de los años 50 y 60 conservados en el Archivo Municipal. Durante algún tiempo sirvió de sede, desde el año 1859, para el importante foro de debates que fue el Ateneo Coruñés; donde se discutían temas de actualidad como el feminismo, la emigración, el provincialismo, etc... ${ }^{17}$. Posteriormente, según refiere igualmente Tettamancy:

${ }^{16}$ TETTAMANCY GASTON, F.: Apuntes para la historia comercial de La Coruña, Tip. de El Noroeste, La Coruña, 1900. Págs. 215 a 218.

17 Incluso la sociedad Circo de Artesanos, en 1859, discutió vivamente sobre la posibilidad de abandonar su local en la calle San Andrés para trasladarse al del teatro que nos ocupa.

ESTRADA CATOIRA, F.: Contribución a la historia de La Coruña por la R.R. e I. de Artesanos... RR. e I. de Artesanos, La Coruña, 1986. Págs. 51 y 52.

"CUADERNOS DE ESTUDIOS GALLEGOS", Tomo XL, Fascículo 105, Santiago 1992. 
"De los años de 1864 al 69, estuvo instalada también en dicho local otra asociación de la misma índole llamada Fraternidad Juvenil... Dicha colectividad ocupó un papel preferente, durante sus ocho años de vida, en La Coruña. Dió muchísimas representaciones teatrales y líricas....".

La larga actividad de este teatro aún conocería temporadas de mayor auge, especialmente en los años comprendidos entre 1867 y 1870 , ya que de resultas del incendio del Teatro principal permaneció como el único local de espectáculos de la ciudad -junto con algún ocasional circo ecuestre- hasta que se completó la reedificación de aquél.

Las últimas referencias que hemos encontrado en las cajas del Archivo Municipal sobre representaciones en el Teatro viejo nos llevan ya al año 1875. En esta misma fecha, siempre siguiendo a Tettamancy:

"A la sociedad Fraternidad Juvenil sucedióle después de algunos años de intervalo en el local de referencia por los años de 1875 al 1878, la que se denominó de Gimnasio y Esgrima, dando excelentes espectáculos y contando también con sus secciones de declamación y canto...

AlGimnasio siguióle la que fue entusiasta SociedadLiceo Brigantino, fundada con muchos elementos de la Juvenil... fue la última asociación que ocupó en el concepto de alquiler el teatro de la calle de la Franja o Pequeño; ella hizo varias reformas en este edificio, construyendo de nueva planta una casa de un piso que había contigua a él, con el objeto de dar mayor comodidad a sus asociados..." 18 .

Entre esas reformas se encontrarían las citadas en 1880 por La Ilustración Gallega y Asturiana en los siguientes términos:

"Creen algunos que una vez que el teatro de Variedades, en la calle de la Franja, ha sido reparado en su parte exterior, patio, palcos y

\footnotetext{
${ }^{18}$ TETTAMANCY GASTON, F.: op. cit. Pág. 217.

Estas obras deben corresponderse con la reedificación de la fachada en 1881, a la que aludíamos en la nota $\mathrm{n}^{\mathrm{O}} 13$.
}

"CUADERNOS DE ESTUDIOS GALLEGOS", Tomo XL, Fascículo 105, Santiago 1992. 
plateas, sería conveniente se fijase su propietario en la necesidad de dar al escenario las condiciones acústicas que necesita. Lo que se gastase en poner este teatro en buenas condiciones escénicas no sería perdido" ${ }^{19}$.

Gracias a esta renovación integral, derivada de su nuevo uso como local social del Liceo Brigantino, el teatro ejerció un gran protagonismo en la vida cultural de La Coruña finisecular. Así, entre otras actividades que acogió, hemos de resaltar la celebración del centenario de Calderón, en el año 1881, con una velada lírico-dramática:

"El salón-teatro de la sociedad se hallaba decorado con el mejor gusto. Grandes guirnaldas de flores orlaban los palcos, de cuyas arcadas pendían caprichosas canastillas, destacándose en el centro, y en el lugar que ocupa la lucerna, una de gran tamaño y artísticamente colocada.

Se puso en escena un cuadro dramático en un acto y en verso, titulado Aniversario, y escrito por D. José Millán Astray...

Cuando se alzó de nuevo la cortina, el busto de Calderón, rodeado de esplendentes rayos, ocupaba el centro del escenario, y los individuos de la sección de declamación depositaron ante el mismo coronas de flores y siemprevivas..." ${ }^{20}$.

Posteriormente aparece mencionado, en una guía de la ciudad del año 1883, como el lindo Teatro de Variedades que hoy forma parte de los salones del Liceo Brigantino ${ }^{21}$.

La historia de este recinto llega a su punto final en el año 1889; fecha en que se procedió a su derribo para levantar, con planos de Faustino Domínguez Coumes-Gay, el inmueble que actualmente ocupa su solar: el edificio Simeón, hoy sede de los Servicios Económicos del Ayto. de La Coruña (Lámina V). Pese a lo avanzado de su cronología, infructuosamente hemos

\footnotetext{
${ }^{19}$ Noticias regionales. Galicia. Coruña en La Ilustración Gallega y Asturiana, nº 14, 18-V-1880. Pág. 184 (1).

${ }^{20}$ El centenario de Calderón en Galicia. La Coruña en La Ilustración Gallega y Asturiana, no 16, 8-VI-1881. Págs. 189 y 190.

${ }^{21}$ ANONIMO: La Coruña en la mano. Guía de La Coruña con el programa completo de las fiestas... Imp. y Est. de Vicente Abad, La Coruña, 1883. Pág. 46.
}

"CUADERNOS DE ESTUDIOS GALLEGOS", Tomo XL, Fascículo 105, Santiago 1992. 
intentado busar alguna fotografía que plasmara el interior o el exterior de este Teatro de Variedades; por ello, por ahora debemos conformarnos con los datos hasta aquí expuestos.

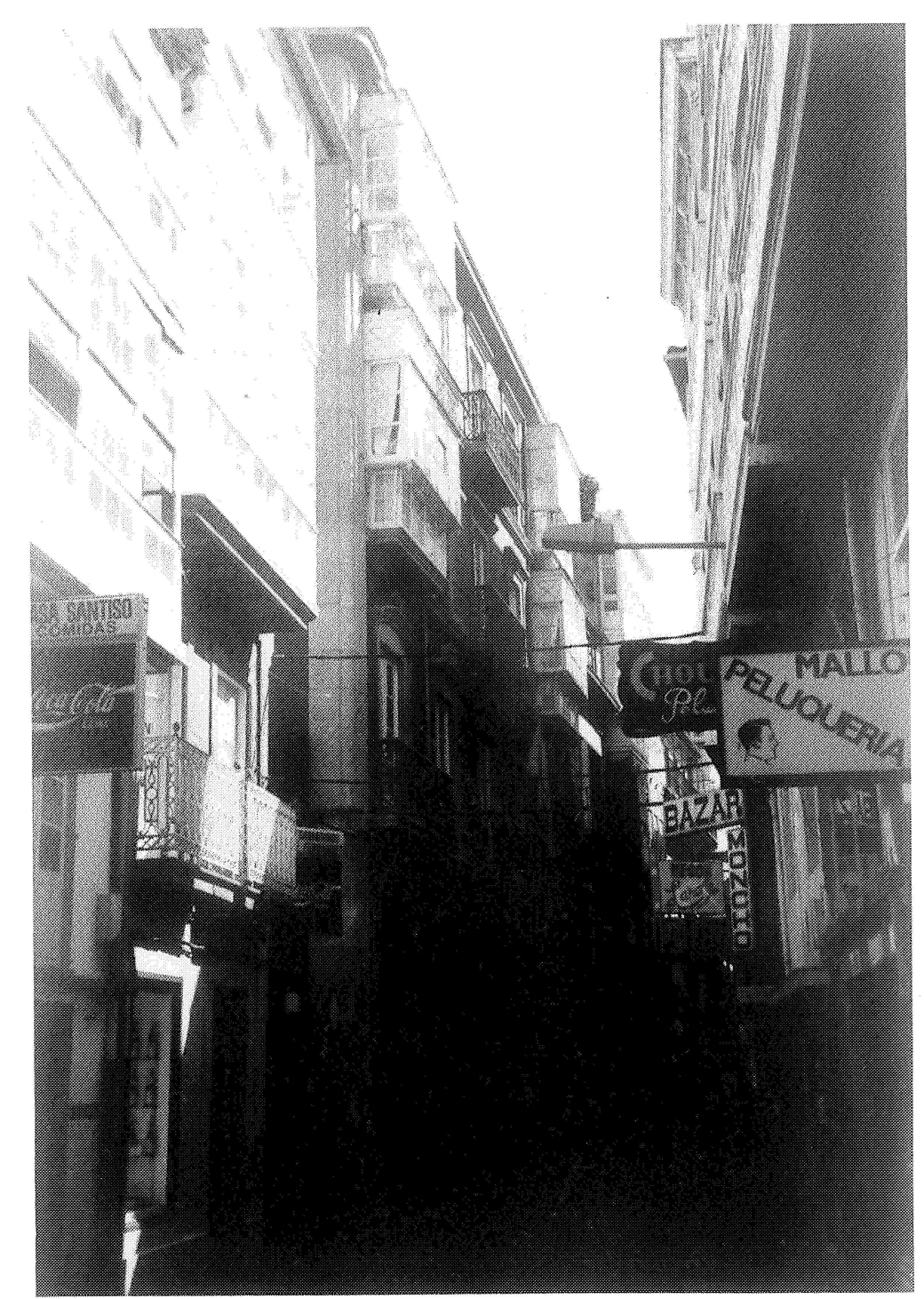

Lámina V: Edificio Simeón. C/ Franja, n 20-22. La Coruña.

"CUADERNOS DE ESTUDIOS GALLEGOS", Tomo XL, Fascículo 105, Santiago 1992. 